\title{
Integrating independent research into science curricula to foster STEM leadership
}

\section{Craig Queenan, Alyssa Calabro, David Becker}

Craig Queenan, Alyssa Calabro, David Becker, "Integrating independent research into science curricula to foster STEM leadership," Proc. SPIE 8729, Scanning Microscopies 2013: Advanced Microscopy Technologies for Defense, Homeland Security, Forensic, Life, Environmental, and Industrial Sciences, 87290F (29 May 2013); doi: 10.1117/12.2015991

Event: SPIE Defense, Security, and Sensing, 2013, Baltimore, Maryland, United States 


\title{
Integrating independent research into science curricula to foster STEM leadership Craig Queenan*, Alyssa Calabro, David Becker \\ Bergen County Academies, Nano-Structural Imaging Lab, 200 Hackensack Avenue, Hackensack, NJ 07601
}

\begin{abstract}
Preparing students for college and future careers is one of the main goals of K-12 education, but current STEM teaching methods do not do enough to interest students and leave them prepared to enter into and succeed in STEM careers. While measures to implement unifying standards for science education across the country are aimed at ensuring that all students are taught the same material at each grade level, a shift in the way science is taught to is needed to complete the redesign of science education. The independent research model described here aligns with the new content standards and focuses on developing the principles of perspective, purpose, resources, collaboration, analysis, and presentation. These principles not only engage students in the classroom, but also leave students prepared to enter into science programs in college and succeed in leadership roles in the STEM workforce.
\end{abstract}

Keywords: STEM, science, research, education, curriculum

\section{INDEPENDENT RESEARCH IN THE CLASSROOM}

\subsection{Making the case for change}

Statistics regarding the state of science and math education in the United States can be found everywhere from education websites to political speeches. The take away message from all of the statistics is simple; current methods in science and math education in the United States are not working, and changes need to be made. Although the message is simple, it is one that has been a concern for decades ${ }^{1}$. So far this year, statistics continue to show U.S. students falling behind in math and science internationally $\left(30^{\text {th }} \text { and } 23^{\text {rd }} \text { respectively }\right)^{2}$, and an unequal distribution and underrepresentation of individuals from low income families and urban centers, females, and minorities entering into STEM related fields ${ }^{2}$.

The problem in the United States is not in convincing people that a change in content and methodology for teaching STEM disciplines must be made, but in the development and implementation of these changes. In terms of the sciences, two main obstacles have stood in the path of change: the lack of a uniform set of science standards and reliance on traditional teaching methodologies. It is only within the past few years that people have started to address these impediments.

The National Research Council (NRC) of the National Academy of Science has been instrumental in advancing the agenda for a uniform set of national science standards. After the release of A Framework for K-12 Science Education: Practices, Crosscutting Concepts and Core Ideas, which made the case for the creation of a national science standard framework, the NRC released a draft of their standards for grade levels K-12, Next Generation Science Standards (NGSS) in $2012^{3}$. Implementation of these standards by all 50 states would be a critical step in advancing science education in the U.S., and would ensure that students in every grade level would be taught the same material and meet the same benchmarks as their counterparts across the country. The importance of such unified standards was shown in an American Institute for Research study in 2010 that showed the gap between student performance in states with the highest science standards as compared to the lowest was as much as four grade levels ${ }^{4}$. Successful adoption of the NGSS, as was seen with the Common Core State Standards in math and language arts, which have been adopted by 45 states since $2010^{5}$, would be a positive step in overcoming the lack of uniformity and accountability in science education across the country.

*craque@bergen.org 1(201)343-6000 x $4645 \quad$ Website: bcts.bergen.org/nsil

Scanning Microscopies 2013: Advanced Microscopy Technologies for Defense, Homeland Security, Forensic, Life, Environmental, and Industrial Sciences, edited by Michael T. Postek, Dale E. Newbury, S. Frank Platek, Tim K. Maugel, Proc. of SPIE Vol. 8729, 87290F · @ 2013 SPIE · CCC code: 0277-786X/13/\$18 · doi: 10.1117/12.2015991 


\subsection{Changing the education paradigm}

In addition to changing what is being taught and expected of students, there must also be a change in the way that the information is being taught. Teachers around the country are developing more student-based and project-based exercises that remove students from the traditional learning environment, but these exercises do not go far enough in changing the mindset of the students and the way they approach and learn science. The independent research model, such as that implemented at the Bergen County Academies in Hackensack, New Jersey and was described in 2012 ${ }^{6}$, supplements science education with hands-on, student developed independent research projects.

Independent research starts with an idea, which is a very powerful motivator for action, progress, and accountability. President Barack Obama stated in his remarks on the launch of the BRAIN initiative in 2013, "Ideas are what power our economy. It's what sets us apart. It's what America has been all about. We have been a nation of dreamers and risk-takers; people who see what nobody else sees sooner than anybody else sees it. We do innovation better than anybody else...We invest in the best ideas before anybody else does"7. In tasking students to develop an idea that interests them, is meaningful to them, is novel, and can be tested using the scientific method, the students stop learning about science and begin learning to understand science.

When students are immersed in the science of their research project, not only do they better understand the information from their classes because they must put it to use, but they also begin to develop leadership qualities, including: accountability, independence, vision for the future, a willingness to collaborate and teach others, and a drive to succeed and produce a high quality result. These leadership qualities develop due to the six principles, or pillars, that education through independent research are built upon.

\section{THE SIX PILLARS OF RESEARCH EDUCATION}

\subsection{Pillar I - Perspective}

Perspective can be thought of as the jumping off point between traditional classroom teaching and independent research. Students gain perspective in three main ways. First, they must be taught the basic principles and theories that have shaped and formed the branches of modern science. This is normally done in a traditional classroom environment, however, that is also where perspective normally ends for the students. Students are expected to learn content and facts, but are not expected to do much else with it other than regurgitate the information in some form of assessment.

In this model, there are two additional ways students must gain perspective. The first comes back to the "idea" that was mentioned earlier. Students are asked what in science or society really interests them, connects with them, or affects them. If given unlimited resources, what question would they want to study, and what problem would they want to solve. This internal perspective can be intimidating, but it allows students to begin to think like a scientist, and creates an immediate investment in the research. Since the student developed the idea, they feel a greater sense of accountability when it comes to its success or failure.

The second way deals with perspective on the current state of science and research, where students must understand what research is currently being done by performing primary literature searches on their topic. This is an important, but difficult stage for the students. Understanding where to go to obtain the journal articles and how to dissect out the important information is a skill that takes practice and patience, but will be valuable for the student beyond high school. Through reading multiple papers on a topic, and with the guidance of the instructor, the student gains the perspective needed to develop the project, and can move on to addressing the purpose.

\subsection{Pillar II - Purpose}

Students doing independent research must understand the purpose of their research on two scales. The first deals with the goals of the project. When developing the project and determining necessary experiments, students must understand the purpose of performing each experiment, the possible outcomes, and the goals that are to be achieved 
at each stage. Understanding the purpose of each experiment forces the abstract information gathered from the primary literature to be focused into a logical progression of tests throughout the project.

Next, the larger scale purpose of the research must also be considered by the student. This greater purpose normally coincides with the student's reasons for wanting to do the project, the internal perspective previously mentioned. Because of the perspective that was gained through the background literature research, students also begin to understand the current state of the field and the importance of where the project would fit into the field. Thus, the greater purpose is understood by the student and is a motivator to work diligently to obtain meaningful results that may contribute to the greater body of knowledge on the subject.

\subsection{Pillar III - Resources}

The tools needed to carry out experimentation make up a portion of the students' resources in a research project. Understanding how to use an instrument and obtain data, as well as determining the best tool to use for an experiment are important skills that a student develops in the experimentation stage of a project.

The techniques that a student learns may be even more important a resource than the tools in the lab. The experimentation stage of the project introduces students to techniques and skills that require practice and precision, and with mastery, are transferable to any future lab environment a student encounters. The quality of results in a project hinges on the careful execution of techniques and protocols by the student.

The final resource that is critical to student success is guidance by the mentor or instructor. Without a mentor who is patient and engaged in all stages of the independent research project, the techniques cannot be properly taught and the tools are rendered useless. The mentor watches over the student after teaching the tools and techniques, but it is the student who is responsible for the success or failure of a given experiment. Although the mentor is critical in guiding the student through the research project, in many if not all cases, it is unfair to expect the mentor alone to be the expert in all stages of the project. It is because of this that students must learn to collaborate with other students and teachers alike.

\subsection{Pillar IV - Collaboration}

Collaborating with other mentors and professionals is important in order to develop additional techniques needed in the research project. The act of discussing the research project with another professional also forces the student to understand the core concepts and methods of the project, question the topics that are still met with difficulty, and intelligently discuss the future direction of the project based on results. As collaboration is a critical part of professional research, it is also a critical step in preparing students for a future in science.

Collaboration with other students is also a necessary part of the independent research project. Students involved in research will collaborate in a peer to peer format, where students discuss topics, review others work, and provide feedback. This peer to peer collaboration is important for the students because it allows for independent growth in the project without the direct oversight and guidance of the mentor. When a student reaches the later stages of research, the student will also collaborate with others in more of a mentor role, where students who are newer to research or struggling with a technique or protocol can receive guidance from the more advanced student.

\subsection{Pillar V - Analysis}

Running an assay or experiment is important in order to obtain data and results. Learning to analyze the results can be a more difficult task. Proper analysis includes dissection and interpretation of the data, plotting data into easy to understand visual charts, and determination of statistical significance.

In addition to analyzing the data, students must also analyze the research project as a whole. By analyzing the overall project, students ensure that the core concepts of the project are understood, that necessary and logical experiments were carried out, and that the data is meaningful and easily understood. Once all of the analysis has been carried out, the student is ready for the culminating stage of the independent research project. 


\subsection{Pillar VI - Presentation}

The experience of carrying out a research project and putting into practice the information that is learned in the classroom is critical in this model, in order to change the way science is taught in this country. However, after all of the lab work and analysis is completed, it is necessary for a student to share the findings in the same way that a professional would. Students must compile the findings of the study in the form of a written report, poster, oral presentation, or in some cases, a publication. This process allows students to practice important presentation and technical writing skills that will be needed in future education and careers. This also allows the students to showcase work that they were involved in for months or even years, and receiving feedback in order to make improvements.

\section{FUTURE STEM LEADERS}

\subsection{Shaping students for STEM careers}

The goal of K-12 education is to prepare students for the advanced education and careers that are to follow. Traditional science education strives to fulfill these goals, but falls short due to lack of student interest and investment. In developing the NGSS, the National Research Council believes that, "learning about science and engineering involves integration of the knowledge of scientific explanations (i.e., content knowledge) and the practices needed to engage in scientific inquiry and engineering design. Thus the framework seeks to illustrate how knowledge and practice must be intertwined in designing learning experiences in $\mathrm{K}-12$ science education" ${ }^{8}$. The justification for independent research enhanced science education aligns directly with the ideals being put forth by the NRC through the new science standards, specifically the integration of knowledge with practice.

This idea of learning through experience is not new. The proverb, "Give a man a fish and you feed him for a day. Teach a man to fish and you feed him for a lifetime," perfectly describes the shift to science education enhanced with independent research. Traditionally, the goal of science education has been to feed students a stream of facts and information that would prepare them for both school and state assessments, but not require students put the information to practical use. Once the assessment passed, the importance of retaining this information has not been impressed upon the students in a meaningful way. However, by teaching a student to do science, the core principles of traditional teaching are reinforced through practice and real-world application. Students learn and understand science, and can see exactly how understanding the information relates to job skills and performance in future education and career environments.

The six pillars are not graded assignments or physical items that students can walk away from an independent research-based program with, but the pillars are lessons and experiences that encourage student growth, independence, and confidence. The lessons and experiences of carrying out an independently developed study inherently cause students to also develop and show leadership qualities. Unlike in a classroom where a disinterested student is not held directly accountable for the lessons, every stage of the research project demands independent accountability from the students. This independence and accountability, as well as having a vision for the direction of the project are hallmarks of effective and successful leaders in society. Learning to collaborate with others and confidently present and defend findings to an audience are also skills that will allow students to perform as leaders in future careers.

\subsection{Implementation and future direction}

The question then becomes how to best implement a system of independent research in the classroom. The model has already shown success in both practice and student performance at the Bergen County Academies (BCA), where student research is incorporated into the curriculum and all tools and experimentation for research projects are carried out at the school ${ }^{6}$. While the BCA model may not be cost and time effective enough to implement in the same manner in every high school across the country. There are other ways, such as university collaboration, regional research centers, and investments in equipment, personnel, and personnel training that independent research in the classroom can be introduced as the standard for science education on a national scale. It is not a question of 
whether or not science education needs to change; it is a matter of how and how soon. Introducing independent research into science curricula effectively answers the question of how.

\section{ACKNOWLEDGEMENTS}

The authors would like to acknowledge the following people for their contributions, dedication and continued support: Dr. Howard Lerner, Superintendent, and rest of the Bergen County Technical School Administration; the Bergen County Technical Schools Board of Education; the Bergen County Executive and the Bergen County Board of Chosen Freeholders; Russell Davis, Principal, and the rest of the Bergen County Academies administration; and the research faculty members: Dr. Robert Pergolizzi, Donna Leonardi and Dr. Deok-Yang Kim.

\section{REFERENCES}

[1] "Science and Engineering Indicators 2010," National Science Board of the National Science Foundation, January 2010. <http://www.nsf.gov/statistics/seind10/start.htm> (4 April 2013).

[2] Hook, L., "U.S. falling behind in supplying science, technology, engineering and math degrees," The Washington Times, LLC, 23 March 2012. <http://www.washingtontimes.com/news/2012/mar/23/help-wanted855590724/> (4 April 2013).

[3] Next Generation Science Standards. Achieve, Inc. 2013 <http://www.nextgenscience.org/> (4 April 2013).

[4] Phillips, G.W., "International Benchmarking: State Education Performance Standards." American Institutes for Research, 2010., <http://www.air.org/news/index.cfm?fa=viewContent\&content_id=1021> (4 April 2013) .

[5] Common Core Standard State Initiative. 2012. <http://www.corestandards.org/> (4 April 2013).

[6] Queenan, C., Calabro, A., et al. "Integrating research and advanced microscopy into the high school curriculum." Proc. of SPIE, 8738 (873811), 1-9 (2012).

[7] "Remarks by the President on the BRAIN Initiative and American Innovation," White House, Office of the Press Secretary, 3 April 2013. < http://www.whitehouse.gov/photos-and-video/video/2013/04/02/presidentobama-speaks-brain-initiative-and-american-innovation\#transcript> (4 April 2013).

[8] National Research Council of the National Academies [A Framework for K-12 Science Education: Practices, Crosscutting Concepts and Core Ideas] National Academies Press, Washington, DC, 10 (2012). 